de methyl. Archives des Maladies Professionelles, 17, 430-433.

Schwartz, F. (1926). Vergiftungsfälle mit methylchloride. Deutsche Zeitschrift für die gesamte gerichtliche Medizin, 7, 278-282.

Verrière, P., and Vachez, M. (1949). Nephrite aiguë grave après intoxication par methylchloride. Lyon Médical, 1, 256-259.
Weinstein, A. (1937). Methyl chloride (refrigerator) gas poisoning. Journal of the American Medical Association, 108, 1603-1605.

Wood, M. W. (1951). Cirrhosis of the liver in a refrigeration engineer attributed to methyl chloride. Lancet, 1, 508-509.

Received for publication 23 June 1975

Accepted for publication 5 December 1975

\title{
Occupational health and safety in Great Britain 1974
}

\author{
M. A. COOKE
}

Albright \& Wilson Ltd, Oldbury, West Midlands, and

Department of Safety and Hygiene, University of Aston in Birmingham

Previous reviewers have commented upon the enormity of the task of producing these annual reports and of their possible co-ordination under the Health and Safety Commission. However, the present series emphasizes their value as documents in addition to the statistical data given in them. It is to be hoped that the reports will not be discontinued in their present format for this would be a loss to all who practise occupational medicine. The various accounts of activities in the occupational health sphere contrast with those of the Department of Health and Social Security, which of necessity report only briefly on matters of considerable interest and concern. HM Chief Inspector of Factories Annual Report (Department of Employment, 1975) is a document which is a model of its kind. With its sister volume, the report of the Employment Medical Advisory Service (Health and Safety Commission, 1975), it combines in a most readable way all the relevant statistical data, comments upon most aspects of the industrial health and safety field, and gives advice, admonition, and encouragement in a form that is entirely acceptable.
It is difficult to abstract this report as it is of such uniform standard, and so important that it should be read and kept for reference by all working in the health and safety field. This review, therefore, will be confined to comments upon several matters of particular importance or general interest. $\mathrm{Mr}$ Hammer, HM Chief Inspector of Factories refers to the Flixborough explosion and the part the Factory Inspectorate played in the subsequent investigation, and draws the conclusion that the Inspectorate may well be required 'to extend its role in prior assessment of major hazards'. This role may also extend in the field of new chemicals and in the detection of previously unrecognized hazards of chemicals already in use. There is the welcome comment that the Inspectorate's facilities for environmental testing are expanding. Together with the work undertaken in industry, it may well be possible for the United Kingdom to play an increasing and valuable part in the development of new techniques for atmospheric and biological testing for industrial hazards. The international work of the Inspectorate is already very considerable. It includes work in the EEC on plant, equipment, 
and tubular scaffolding as well as involvement in prospective European legislation. Co-operation with all countries is welcome and there is a healthy exchange of visits and attendance at conferences.

A short review on the problem of carcinogens with some examples of work proceeding in the Department remind us of the increasing importance of this problem. At the same time it puts the whole matter in perspective by pointing out that the identification of carcinogens results in better conditions of work and consequently in a diminished risk to the employee.

It properly draws the conclusion that 'the commonsense approach is to expect from industry good general standards of environmental hygiene, dust and fume control, washing facilities, and personal protection whenever chemical substances are handled. Where a threshold limit has been established then it must be carefully observed so that even if additional evidence leads to a lowering of a threshold limit value we will at least be sure that substance was sensibly used within the known standards of a particular time. Such discipline, even in the absence of full knowledge, will almost certainly contribute to reducing the number of occupationally caused cancers'. It is both a realistic and scientific approach to a difficult subject, but in addition to protecting against carcinogens, such a philosophy would also protect against other potential hazards of a noncarcinogenic nature. We cannot guarantee absolute safety, all we can do is give reasonable protection against the known hazards at any particular time.

There is an interesting comment on the carcinogenicity of mineral oil, explaining an exercise in which Factory Inspectors visited factories and studied the general knowledge of both employers and employees of the hazards. It was found that although employers were generally aware of the hazards there was much less awareness among employees. This is a sad comment, for the notices and leaflets issued by the Department are fully explanatory and should be posted and given to all employees who handle mineral oil.

The report contains a most interesting brief history of the Factory Inspectorate from 1833-1974. In speaking of the future of the Inspectorate, it comments 'the District and Divisional structure still remains but proposals are already being implemented which will cause radical changes in this structure. The General Inspector will become a member of a team specializing in the inspection of one or more groups of industries, and in this work he will have the use of comprehensive instrumentation for quantifying the hazards'.

The Factory Inspectorate has begun to move away from the concept of cyclical inspection towards the era of specialist inspection, a course which is necessitated by the intricacies and sophisti- cation of modern industries. This is a move which will be welcomed by occupational health physicians who are experiencing the same problems in their own work.

The report of the Employment Medical Advisory Service (EMAS) for 1973 and 1974 (Health and Safety Commission, 1975) should be read as a companion volume to the Annual Report of HM Chief Inspector of Factories (Department of Employment, 1975), and is of the same high standard.

Dr Gauvain, then the Acting Chief Employment Medical Adviser, describes the early days of the Service and the philosophy behind its work. The close liaison between the Service and other governmental agencies and medical practitioners is emphasized, and the value of personal contact is stressed. The comment is made that the Society of Occupational Medicine expressed grave doubts about its future relationship with the Service at the time of its launching, but the report goes on to state that good working relationships have been established at headquarters, regional, and area levels between the Service and occupational health physicians. Occupational health physicians would go further than this and say that the doubts that they may have had initially have been entirely dispelled. Relationships are indeed of the most cordial and the two-way exchange of information has been valuable.

Dr Gauvain gives credit to Dr Lloyd Davies 'under whose direction first the Medical Services Division of the Department of Employment and then the new Service itself was established and who was the Chief Employment Medical Adviser until his retirement in January 1974'. Dr Gauvain should also be congratulated for the way in which she has progressed the work since that date and established cordial relationships not only with occupational physicians, but with all workers in the health and safety sphere and with industry itself.

The report discusses recent developments in the recognition of long-term health hazards, in particular those of deep sea diving, exposure to noise, and vinyl chloride. There are valuable appendices and clearly presented statistics of industrial disease, together with useful information on addresses, EMAS leaflets and publications, Factory Act Regulations requiring medical examinations, and an appendix of publications by EMAS staff. There are also appendices dealing with medical documentation of the Youth Employment Service and handicapped school leavers, which may not be generally known.

The section on health hazards at work contains many interesting case histories which all clinicians should study. It is sad that so many of these have to be repeated over the years, but this makes it all 
the more essential for them to be included in such a report as this. An example is that of arsenical poisoning: the wetting of metallic dross containing arsenic should be well known as a source of emission of arsine but regrettably cases still occur.

The section on research is fascinating. The research function of the Service is described in great detail and it will at once be apparent that if this is to be fully effective there must be the closest co-ordination with established occupational health services as well as research bodies. There must be a mutual trust which will enable this free exchange of information to take place on both an ethical and acceptable basis. It is clearly the intent of the Employment Medical Advisory Service to achieve this and it could well have an important role to play in the continuing integration of research activities in close association with the Medical Research Council.

Many of the research studies described are necessarily ongoing surveys and it could well be that, in view of the long-term nature of many industrial hazards, the EMAS should set up a voluntary register of research work in occupational disease and medicine. Perhaps the EMAS report would be a suitable medium for the publication of such a register and place the Service in a unique position to assist in the integration of effort.

The report mentions that more extensive use could be made of the statistical evaluation of sickness absence records and also points out the difficulties of this, especially that the absences may reflect causes other than truly medical. Nevertheless sickness absence records can occasionally be valuable in indicating risk areas. It would be unfortunate if the opinions of some physicians that they should not be required to complete sickness absence certificates for industrial organizations or insurance purposes, should deprive research workers in the occupational health sphere of such information in the future.

Cancer registration is stated to be 'at present at a relatively early stage of development on a national scale and there is necessarily a delay between diagnosis and notification'. Several areas such as the Birmingham Region have highly developed cancer registries and it is to be hoped that this will be extended to other areas as soon as is reasonably practicable.

The work of the Central Reference Laboratory is up-dated especially in respect of their lead studies. The work of the EMAS with disabled people and rehabilitation and with young people is an area with many difficulties and administrative problems. These have been faced by the new Service in a positive way. It is encouraging to read of the advances in both of these important fields.

The section on the organization of the EMAS is useful. Particularly interesting is the section on the training of employment medical advisers.

The reports on the Offices, Shops and Railway Premises Act 1963 for 1973 (Department of Employment, 1974), the Alkali, etc. Works 1974 (Department of the Environment, 1974), and those of HM Chief Inspector of Mines and Quarries for 1974 (Department of Energy, 1975a) and the Safety in Mines Research Establishment for 1974 (Health and Safety Executive, 1975) are of a more specialized nature, but contain much valuable data. The first of these has interesting case histories and informative lists of publications, statutory instruments, and type of accident. There is also the seemingly inevitable list of prosecutions.

The Report on Alkali etc. Works is more technical but it may be studied as much by historians as by scientists for it is the last to be presented under the Alkali Acts. Mr Ireland, the Chief Inspector, pays tribute to his predecessors and colleagues and he is justified in so doing for the comment of a Commonwealth official that our air pollution control is 'probably the best and most complete system of control in the world' is well justified.

The Report on Mines and Quarries deals fully and adequately with their current health and safety problems but also discusses many matters of general concern. There are comments on refuse tips and useful data and case histories of fires, explosions, and dust problems. This is elaborated in the Annual Report of the Safety in Mines Research Establishment (SMRE) (Health and Safety Executive, 1975) which contains data on the technical aspects of explosions and fires and the experimental detail given is concise and informative. The section on respiratory apparatus describes useful laboratory testing procedures, as does that on respirable dust hazards.

The dissemination of information is an important and welcome function of SMRE and the report ends with a review of its work, synopses of recent publications, lists of other publications, digests, and useful references.

The Health and Safety Executive inherit a great tradition of confidence by responsible industry in the skills, wisdom, and philosophy of these law enforcing agencies and this is well demonstrated in these several reports.

Although the details of the Digest of Pneumoconiosis Statistics (Department of Energy, 1975b) will be of concern only to the specialist in the pneumoconioses, there are several features which render the document interesting and useful. The authors carefully remind the reader that, apart from the National Coal Board (NCB) data, the tables are based on claims for benefit only and do not give the actual incidence of the disease. However the NCB scheme provides for a five-year periodic chest radiograph and prevalence figures for various 
levels are available for the coal mining industry, 'which accounts for over $65 \%$ of the new cases diagnosed each year'.

Several of the tables contain data relating to industries other than coal mining. The cases first diagnosed relate, generally speaking, to dust conditions of many years ago and to that extent it is gratifying to see a decrease in the annual number of deaths in many industries including mining and pottery manufacture; but foundry workers and asbestos workers do not show such a welcome fall. We await future reports which it is hoped will provide evidence of the effectiveness of measures introduced in the past few years.

The introduction provides a useful resumé of the procedure for assessment of disablement and refers to the National Insurance (Industrial Injury) Act, the Workmen's Compensation Act, the Pneumoconiosis, Byssinosis, and Miscellaneous Diseases Benefit Scheme and the work of the Pneumoconiosis Medical Panels and the Silicosis Medical Board (staffed by the same doctors).

The first section of the Report on Safety, Health, Welfare and Wages in Agriculture (Ministry of Agriculture, Fisheries and Food, 1972) relates to the work of the Agricultural Wages Board and the second section to the work undertaken by Ministry staff on health and safety, but as the introduction explains, the two aspects interlink. More sophisticated machinery is expensive and requires experienced and proficient workers.

Injuries resulting from tractor accidents still cause concern but the increasing number of tractors fitted with safety cabs has lessened the hazard and there has been a progressive diminution of fatal tractor accidents for the period 1967-72. The improvement in guarding of machinery has also been significant.

There has been an increasing awareness in the agricultural industry of the effects of excessive noise and the Agriculture (Tractor Cabs) (Amendment) Regulations 1973 limit the noise inside tractor cabs at the driver's ear to $90 \mathrm{~dB}$ 'for cabs fitted to tractors first sold for use in agriculture from 1 September 1975 and for all cabs sold after 1 September 1977'. It has proved possible to achieve levels well below $90 \mathrm{~dB}$. Until the Regulations become fully effective, personal ear protection is being advised by the Inspectorate.

While the total number of fatalities has decreased, the number of fatal accidents to children which comprises almost a quarter of the total still causes considerable concern. While many channels of communication are pursued, the report emphasizes that this is of no avail without the help of all adults. Regulations will not protect the child unless the adult co-operates and accepts the responsibility for his children or those on his property.
Falls are the largest single cause of absence from work ( $23 \%$ of non-fatal accidents) but many accidents are due to poor servicing and maintenance of machinery.

Poisoning continues at a low level, to the credit of manufacturers, farmers, contractors, and workers who design and conform to the safety precautions on product labels.

The Department continued to co-operate with the European Economic Commission (EEC) in the harmonization of safety and health legislation, with the European Free Trade Area (EFTA) on the testing of agricultural machinery and tractors, and with the Organization for Economic Co-operation and Development (OECD) on safety regulations affecting manufacture of agricultural machinery and tractors, the last work being transferrred to ISO in 1973.

Deaths occurred from Weil's disease (1), tetanus (1), and farmer's lung (2), while non-fatal disease notified by the DHSS included ringworm (12), Weil's disease (7), tetanus (1), non-infective dermatitis (36), farmer's lung (15), and tenosynovitis (91).

The report on Casualties to Vessels and Accidents to Men (Department of Trade and Industry, 1974) is necessarily incomplete in respect of mortality figures for, as carefully explained in the text, it does not include deaths of seamen on shore in the United Kingdom, even though the accidents occurred at sea. Nevertheless it provides valuable statistics and interesting reading.

The report is divided into three parts:

Part I (Merchant Vessels) includes deaths from disease and it is interesting, although perhaps not surprising, that more than one-third of these deaths resulted from coronary thrombosis. There were 30 deaths from suicide (25) and homicide (5), compared to 137 deaths from disease.

Part IIA (Deep Sea Trawlers) and Part IIB (Fishing Vessels-other than Deep Sea Trawlers) detail types of accidents but not disease, presumably because data on diseases would be very incomplete in these groups.

Finally the Annual Report for 1974 (Department of Health and Social Security, 1975) provides a wealth of data which should prove useful to the social scientist or to those interested in the progress of the National Health Service. The contents are of little direct value to the practising occupational physician, if only because they are already in many instances outdated by changes in the NHS and inflation, and it would be unwise to rely upon data in this report as a basis for practical advice without considering these factors.

The complexity of the Service is apparent to the reader of these annual reports and there are some who will consider that government could have simplified the organizational structure. 
The few comments on smoking and health give little cause for optimism, and the section would have been better entitled 'Smoking and disease'. It should by now be clear that voluntary agreement is quite inadequate to deal adequately with this major hazard.

The report refers to drug dependence and alcoholism, both problems which seem to be still increasing. The Advisory Committee to study alcoholism was chosen for the personal contribution it could make rather than as a representative of any particular organization or interest.

Comments on staff health are lacking and there is no reference to providing occupational health services for DHSS employees.

The current series of reports make enjoyable reading and are particularly encouraging in the interest expressed in several for full co-operation with industry. They are valuable sources of reference and the prices in these inflationary days are most reasonable.

\section{References}

Department of Employment (1975). HM Chief Inspector of Factories Annual Report 1974. HMSO, London.
Department of Employment (1974). Annual Report of the Offices, Shops and Railway Premises Act 1963 for 1973. HMSO, London.

Department of Energy (1975a). Report of HM Chief Inspector of Mines and Quarries for 1974. HMSO, London.

Department of Energy (1975b). Digest of Pneumoconiosis Statistics for 1973. HMSO, London.

Department of the Environment (1974). IIIth Annual Report on Alkali etc. Works 1974. HMSO, London.

Department of Health and Social Security (1975). Annual Report for 1974. HMSO, London.

Department of Trade and Industry (1974). Casualties to Vessels and Accidents to Men, 1972. HMSO. London.

Health and Safety Commission (1975). Employment Medical Advisory Service. A Report of the Work of the Service for 1973 and 1974. HMSO, London.

Health and Safety Executive (1975). Annual Report of the Safety in Mines Research Establishment for 1974. HMSO, London.

Ministry of Agriculture, Fisheries and Food (1972). Report on Safety, Health, Welfare and Wages in Agriculture, 1972. HMSO, London.

Received for publication 21 June 1976 Accepted for publication 23 July 1976 